\title{
Production of Ceramic Wares with Idea Development from Shells to Promote Femininity in Ghanaian Pottery
}

\author{
Mercy Abaka-Attah, Kofi Asante-Kyei, Alexander Addae \\ Department of Ceramic Technology, Takoradi Technical University, Takoradi, Ghana \\ Email address: \\ mercy.abaka-attah@ttu.edu.gh (M. Abaka-Attah), kofi.asante-kyei@ttu.edu.gh (K. Asante-Kyei), alexander.addae@ttu.edu.gh (A. Addae) \\ To cite this article: \\ Mercy Abaka-Attah, Kofi Asante-Kyei, Alexander Addae. Production of Ceramic Wares with Idea Development from Shells to Promote \\ Femininity in Ghanaian Pottery. American Journal of Art and Design. Vol. 4, No. 2, 2019, pp. 8-14. doi: 10.11648/j.ajad.20190402.11
}

Received: July 13, 2019; Accepted: August 6, 2019; Published: August 19, 2019

\begin{abstract}
Ghanaian pottery practices and their modern reintroduction have been rendered masculine especially in tertiary institutions. Feminine participation in contemporary Ghanaian pottery/ceramic practices is virtually non-existent. The study believed women's participation had contributions to make to pottery practices, and hence advocated the employment of feminine subjectivities and traditional spaces as well as indigenous pottery trade strategies and other feminine idiom within contemporary studio practices as means to rescue the stagnating practices and involve womanhood in the evolution of ceramic art at tertiary levels. 'Modelling' and 'throwing' were the main studio forming methods employed to produce crockery in the study. Materials used included; Abonko and Mfensi clays, manganese and glaze. Again, the study explored means and bases for feminine inclusion, especially in contemporary and academic pottery practices as means of normalising an anomaly engendered by maternity. It concluded among others that, pottery practices in their modernist sense had been trapped in sculpture representations and it was only through the use of feminine idioms and subjectivities that they ought to be freed to their full meanings as art. It was recommended with others that, female students would be given the chance to develop concepts that would depict their inner values and beliefs in their wares.
\end{abstract}

Keywords: Crockery, Feminine Idiom, Pottery

\section{Introduction}

Pottery is among the oldest arts of mankind and according to Perani and Smith [1], before the twentieth century, Africans of the south Sahara had no knowledge of the potter's wheel and therefore clay vessels were hand-built. Barley [2] has also indicated that, hand-built vessels dates back to the early fourth millennium B. C in Nigeria and in the Saharan sites, vessels found have been dated to the eighth millennium B. C. Anquandah [3] further reveals according to his archaeological account that, literally, every district or region in Ghana provide some evidence of remains of ancient clay hearths, smoking pipes and vessels for cooking or serving food, carrying, storage and serving of water. All the above mentioned vessels are used domestically with some few of them intended and used for religious or magical purpose and since women were and are directly linked to managing the home; it was only prudent for them to produce these items to aid them in executing their homely duties. Rattray [4] has also established that in the Ashanti traditional setting, it is noted that the first potter was a woman called "OsraAbogyo" who hailed from Tafo village. It is believed that she learnt the art from "Odomankoma", that is God the creator.

Females were engaged in gathering, cultivation of crops, making pots, preparing food and drinks, selling goods in the market and even fishing and weaving just as their male counterparts. Again, Berns [5] has said that women dominated the production of ritually-destined figurative ceramics in Nigeria. Through such production women play important roles in the construction of social and cultural meanings. Perhaps in other parts of the world, the concern is with appearances than with meaning but the study of the uses and meanings of pots of the past, its understanding and content can be infused into the development of the present day work. According to Annan [6], the traditional woman is not limited to only domestic roles but has inner strength to combine domestic work with other challenging roles in the society as a whole. This emphasizes how important females are in all spheres of life and would play a critical role in 
promoting pottery making at the tertiary levels in Ghana's system of education.

\subsection{Statement of the Problem}

Ghanaian pottery practices and their modern reintroduction have been rendered masculine especially in tertiary institutions. Feminine participation in contemporary Ghanaian pottery/ceramic practices is virtually non-existent. Various perceptions and myths have been associated with male dominance of pottery and ceramics at higher education sector. It is against this backdrop that the study seeks to promote femininity in Ghanaian pottery, especially at the tertiary level by producing ceramic wares with emphasis on crockery with idea development from shells.

\subsection{Objectives of the Study}

1. To identify an appropriate shell to produce ceramic crockery to represent femininity in Ghanaian pottery.

2. To explore different finishing techniques to depict antiquity and contemporary touch to inspire female ceramic artists.

\subsection{Research Question}

To what extent can ceramic wares developed from shells promote indigenous feminine pottery practices?

\subsection{Importance of the Study}

The study will be useful to ceramic artists, especially female students in tertiary institutions where ceramics programmes are offered in order to promote feminine pottery practices.

\subsection{Delimitation (Scope)}

The study is limited to developing ideas from shells to make ceramic crockery.

\subsection{History of Women's Dominance in Pottery Practice}

Women engage in pottery making because they have the skill, the right attitude, the endurance and the patience for it [7]. Traditional pottery is mostly done by hand and this enables the potter to exhibit her individual skill in her approach. Barley [2] maintains the production of usable vessels within the framework of a traditional canon of forms demands technical ability. This technical ability cannot be acquired without the expenditure of great time and constant practice. Women are naturally endowed with endurance and patience and these are attributes needed in the production of pottery. Additionally, the fact the pots are hand-made, and women potters have the requisite skills, the time to spend as well as the endurance for the risks associated with pottery, they make forms based on their personal feelings and style. Rattray [4] adds that, in ancient times, it was women who produced pottery products because invariably, pots were bartered in exchange for food and women were and are in charge of cooking food for the household. Women were often noted for pottery as the hand-building methods used meant that the work cycle was regularly interrupted to allow the part-built vessels time to become leather hard before being completed; and this fitted in well with women's domestic role in such societies [8]. Pots were never sold for money as is the case now; they were produced for barter and domestic use. Priddy [9] has established that among the Shai of the Accra plains, it is practically compulsory for every girl to learn the art of pottery in order to be fully accepted as a member of the society. These clearly indicate that women have indeed dominated the art since its genesis. Again women dominate the pottery industry because the art of pottery making requires a great deal of patience and nurturance; attributes that are more feminine. Making pottery also requires abiding by the conservative rules which is time and regular practice and again, women are noted for that which means they have advantage over men in this regard.

\subsection{Nature and Arts (Inspiration-Selection of Seashell Species)}

Forms in nature are said to be similar to pottery forms, for instance, there are seed pods that look like vessels. Lines and textures seen in plants and trees are reminiscent of the forms reproduced over the centuries in clay [10]. Taking inspiration from nature has bred artistic prowess in many artists. Tourtillott [11] is of the view that contemporary pottery has become more sculptural and this is widely in its form and approach, with little the field seems incapable of embracing. These have been made possible because the makers have been inspired by abstraction and nature. The same cannot be said of our indigenous potters because pottery forms before the introduction of pottery did not see much abstraction as it is the order of the day now. Our women drew inspiration from their natural environment and their domestic needs and so produced wares for utilitarian purpose. Lately, pottery wares have become aesthetically appealing objects other than functional. Drawing inspiration from nature to create an artwork that serves a dual purpose requires high intellectual prowess. An artist is able to develop concepts either from natural or manmade source. Natural objects, especially seashells are generally endowed with unique and fascinating forms, shapes, colours, textures and they serve the purpose of aiding an artist in developing and pursuing his passion. This, however, makes it possible for an artist to creatively produce pieces to serve both decorative and utilitarian purposes.

Inspiration was drawn from seashells with diverse shapes, sizes, patterns and colours from the five classes. Some interesting seashells out of the lot were finally selected and that provided adequate ground which broadened the scope for the concept. According to Quinn [12], design development describes a number of activities that help to develop the concept and ideas to their fullest potential. This can involve sketching, brainstorming and prototypes. It should be a rigorous and rewarding process, a thorough investigation of an artist's ideas. This study seeks to use seashells to portray the beauty of femininity associated with indigenous pottery forms and practices as well as how they have been used in the past. 


\section{Materials and Methods}

\subsection{Idea Development}

Thorough study of the various seashells was done and that gave a broader view of the kinds of wares that could be produced based on indigenous pottery practices. No sketches were used to record the series of ideas which were developed from studying the seashells. By observation, most of the seashells could be used in their natural state as kitchen wares because of their shapes and colours. An example was the Trophon shell from the Muricidae family of seashells as shown in figure 1.

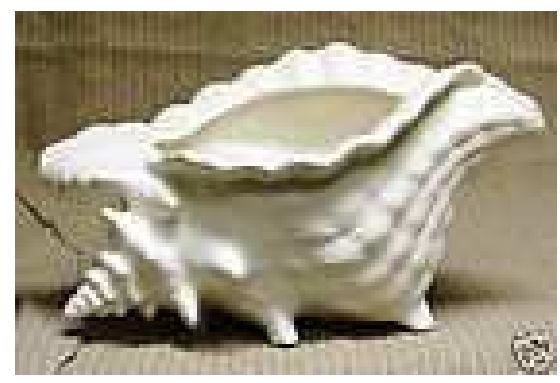

Figure 1. Trophon shell.
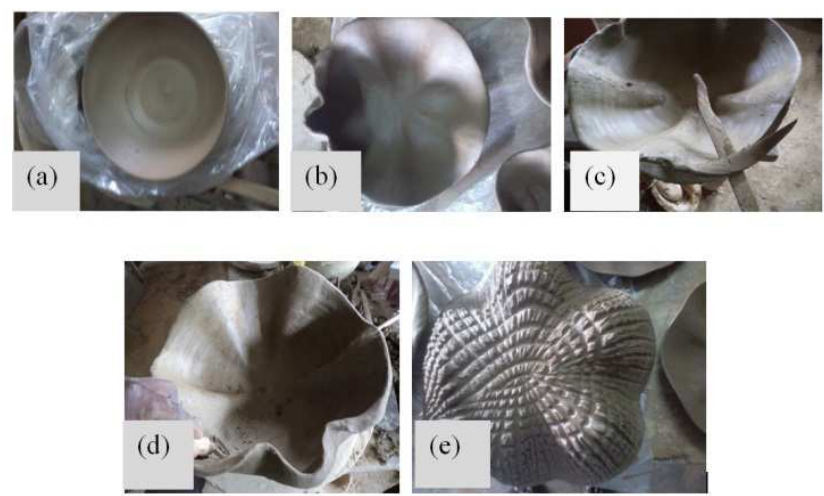

Figure 2. Pictures showing the stages of the making of fruit and salad bowls from seashell concept in clay. (a) a thrown bowl (b) manipulating to get the shape of a seashell (c) reshaping the bowl (d) cleaning the bowl (e) outer decoration of the fruit bowl.

It was evident in the picture in figure 1 that ideas could be developed from that shell to produce unique wares not only in clay but in other media as well. It was upon this premise that the idea of kitchen wares having the shapes and decorations as the seashell were developed.

\subsection{Materials}

Materials used in the study included Abonko and Mfensi clays, manganese, and glaze. The clays were obtained from Abonko in the Central Region and Mfensi in the Ashanti Region of Ghana respectively.

\subsection{Forming Methods}

'Modelling' and 'throwing' were the main studio forming methods employed in manipulating the ideas from seashells with feminine features into functional pieces like fruit bowls, plates, teapots, tea cups and saucers, and serving bowls as shown in figure 2 . The fruit and salad bowls were thrown and allowed to dry to a workable state before the manipulation process began. The bowls went through various stages of handling until the required features of the seashell was achieved.

Similarly, the serving plates, salad bowls, teapots, flower vases were also worked out from thrown pieces following the same procedure that was adopted in the making of the fruit bowls as described initially. Other domestic wares produced were the bowls with lids and open bowls. These wares came in sets of three and five; the same procedure was used in making all of them. With the making of the tea set, 'throwing' and 'modelling' were the main forming techniques employed as every piece was 'thrown' and the tea pots were manipulated to possess features of the seashell. The cups and saucers were only decorated to possess some textures of the seashell but did not see any manipulation in their forms. Pictures showing the processes in the making of the bowls with lids are shown in figure 3 .
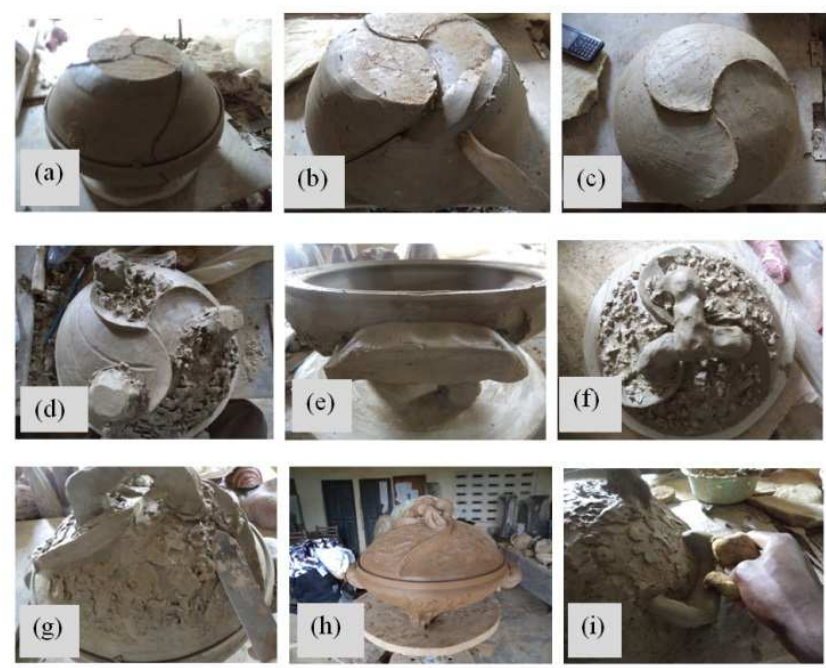

Figure 3. Pictures showing the making of the serving bowls (a) thrown bowl and lid, (b) demarcated lines for the foot and handle, (c) demarcated lines for foot and handle, (d) fixing of foot, (e) fixed handles on the bowl, (f) fixed handle on the lid, (g) decorating with a knife, (h) finished bowl with lid, and (i) cleaning with a foam.

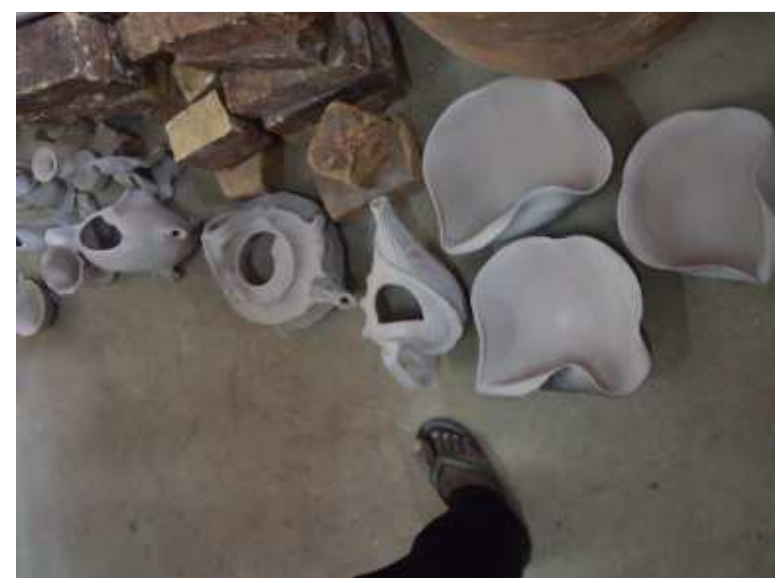

Figure 4. Picture showing bowls and teapots with seashell features. 


\subsection{Drying, Firing and Finishing}

After creating all the various forms, some products were decorated by incising lines and creating textures on them. Others were also coated with clay slip of different colours to break the monotony and create variety and harmony in the pieces. After decorating them, pieces were allowed to dry in the shade to control rapid drying which could cause the wares to either warp or crack. At the bone dry state, some of the wares were fired using the gas kiln whereas others were fired in an electric kiln. Both kilns were used to observe the outcome of the effects of reduced and oxidized firing methods for further recommendations. It was observed that in the event of light out or no source of electricity, gas kiln could be used and almost the same result would be achieved; as that was clearly evident in the wares fired with either kilns.
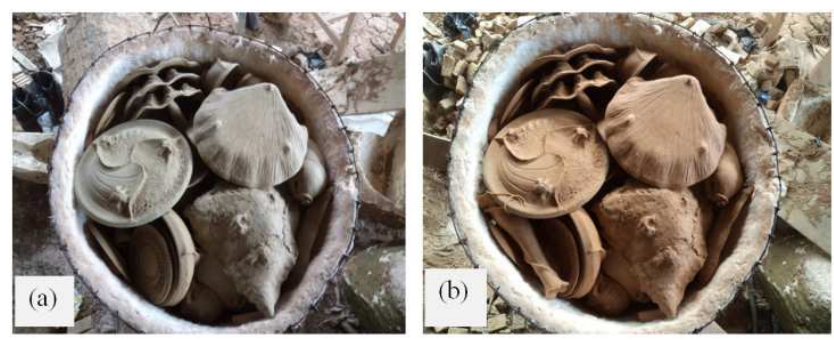

Figure 5. $(a \& b)$ The ceramic crockery made from seashells in bone dry and state bisque state.

The bisque fired wares were later segregated for the applicaiton of finishes in glaze, and manganese washing. To create an antique finish for the manipulated shell pottery wares, the outer sections were coated with manganese and later washed to leave graded tones of black and buff as shown in figure 6 (a). However, for some other pottery wares, both the inner and outer areas were glazed as exhibited in figure $6(\mathrm{~b})$. This was done to put the wares in a condition where they could be used domestically in the homes apart from the aesthetic value that they possesed; having a bearing on indigenous pottery type.
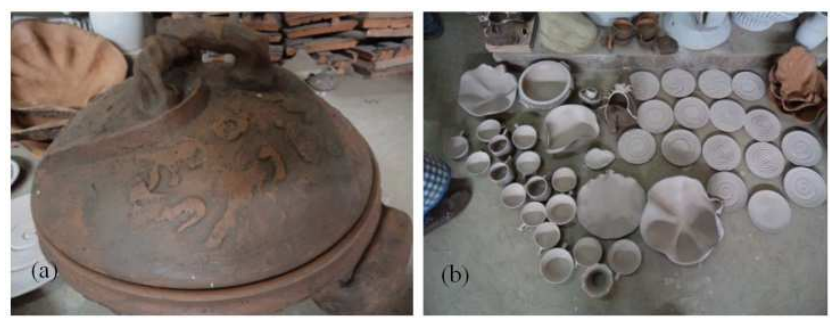

Figure 6. $(a \& b)$ The application of manganese outside and glaze inside the pottery wares.

\subsection{Gloss Firing}

This is the second and final firng of ceramic wares. The crockery treated in manganese and glaze were carefully arranged in an electric kiln as shown in figure 7 and fired at a temperature of $1180^{\circ} \mathrm{C}$. The firing lasted for about 10 hours after which the kiln was swithed off and allowed to cool for
24 hours before it was opened for the wares to be removed.

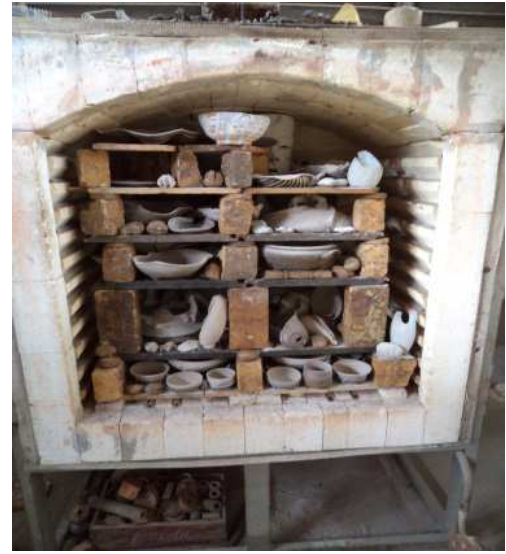

Figure 7. Packed kiln with crockery for gloss firing.

\section{Results and Discussions}

The motivation for the study was to explore strategies to bring back the female craft and thus, make contemporary pottery take the meaning of the indigenous context. 'Modelling' and 'throwing' were the main studio forming methods employed in producing the crockery with indigenous practices touch. Ideas were developed and ceramic crockery forms which had seashell features were produced. Glaze was applied to the inner surface of the crockery that fused with the body and formed an intimate association that affected the finished surface. Manganese was applied to the outer surface which gave the crockery an antique look and touch.

The production of the crockery based on seashells and the application of contemporary production methods, for indigenous effects, is to be seen as a model to illustrate that, the development and sustenance of pottery as a craft depends on the potential contribution of women. Finally, the study has hyped the effective understanding of indigenous pottery as philosophy has focused on the means of merging both indigenous and contemporary ideas, as well as forming and finishing techniques as a redirection for Ghanaian ceramic and pottery practices.

\subsection{The Feminine Touch to Pottery}

Hopper [12] has indicated in figure 8 that, vessels are the universal feminine symbol; the womb of the Great Mother, shelter, protection, preservation, nourishment and fertility and that, they represent inwardness and inner values; bowls represent giving or offering and fertility.

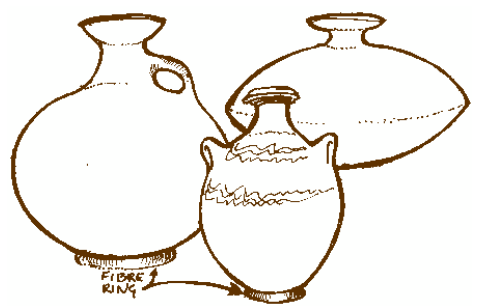

Figure 8. Indian and African water jars. Hopper (2000). 


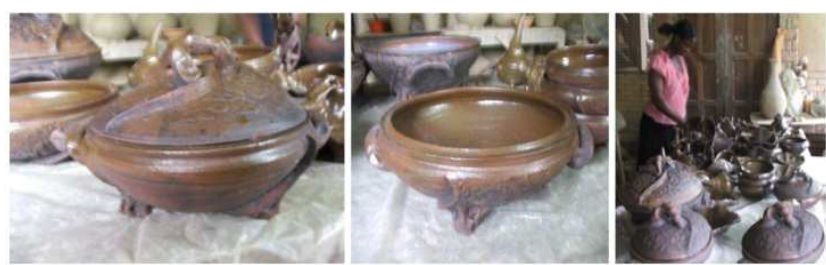

Figure 9. Table wares finished in manganese and glaze.

The crockery as seen in figure 9 is a representation of Hopper's [13] assertion that by contemplation and study of the uses and meanings of pots of the past, one can infuse a greater understanding and content into one's own developing works. Clay vessels were made for a variety of reasons and purposes. Our varied cultural values, habits and geographical locations greatly influence the kinds of objects to make; thus whether functional or decorative or to serve both purposes. Each piece that was produced was very useful in essence because of its shape, form and function.

The crockery was produced to hold food and water which are very essential basic needs of every living thing. Women generally are responsible for the preparation of food in every family setting and thus, the crockery becomes one of the tools needed to enhance the cooking and serving of food. Without the spaces in these clay vessels, their meaning and usefulness would be thwarted. The usage of the sea shells as research idiom brings on board a viable source of inspiration in nature that can spur up women's productivity in contemporary pottery. With sea shells as the main object of inspiration and feminine features, women could produce variety of domestic wares ranging from bowls, cups, plates, cooking pots, lamp shades, light holders and flower vases that meets the aesthetic demands of contemporary pottery. This hunch is established in the manner the sea shells have been manipulated into tea sets, bowls, fruit bowls, light holders and flower vases. Though the wares are functional, their attractive features derived from the sea shells give them other aesthetic qualities that promote feminine participation in contemporary pottery production.

\subsection{The Domestic Pottery}

Domestic wares such as bowls, plates, cups, grinding bowls, cooking pots, and others have been taken over by plastics and water coolers are no longer attractive to the contemporary man due to technological advancement which has led to the manufacture of refrigerators and water dispensers. This situation has caused female participation and general consumption of pottery products to dwindle in this modern era. Though plastics products dominate today's domestic wares because of its durability, light weight and low cost, it has a negative effect on humans and the environment. Serving hot foods in plastics can increase the risk of kidney stones and also serving acidic foods in plastic can cause melamine products in plastics to contaminate the food [14].

In order for domestic pottery products to fit into contemporary era of products, domestic pottery products were developed and produced from sea shells in this study.
The essence was to make them more stylish and to serve both utilitarian and decorative purposes as demonstrated in figure 10. Again, this study also serves as a basis for formally trained women in the art to engage in different styles of productions that fit into contemporary line of products and still maintain the content of domesticity in their wares.

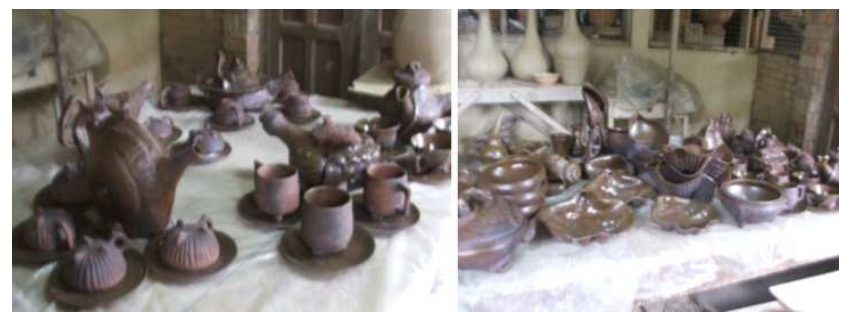

Figure 10. Table wares made by manipulating seashells, finished in manganese and glaze.

\subsection{Finishes}

The choice of finishes for pottery could be influenced by the purpose the product is intended for as well as what the artist wishes to portray in his pieces and as an artist, the ability to make good use of available raw materials to produce a work of art provides a unique style that distinguishes the artist to that finish. Both indigenous and contemporary pottery practices have experimented and acquired different means of finishing pottery wares. Garth Clark as cited in Vicchio [15] suggests that a new way of appreciating pottery wares or clay vessels is to treat the entire pot as an image. Firing pottery products to relatively low temperatures in bonfire-firing; which are still in use in some parts of the world today made the pots porous but the pots were reasonably efficient [8]. Cooper [8] further states that the porosity was a desirable feature for pots intended to hold water in a hot climate as the constant evaporation from the outside helps keep the content cool. As the needs of man kept changing, finishes like burnishing was devised to render the pottery wares impervious, increase its strength and make the surface smoother while other pots had the surface painted with vegetable 'glaze', especially in Africa to achieve same results. The styles of finishes applied to clay products keeps widening as modern applications give room to explore multiple materials in order to acquire the most appropriate finish for a particular pottery product. In the traditional way of improving the aesthetic of pots, potters in the region solely depend on incision and smoking as finishing for their pieces.

The crockery produced by manipulating sea shells were finished in both glazes and manganese. The choice of manganese for the outside and glaze for the inside was for the wares to have an antique touch and at the same time be useful. The idea was to depict the look and touch of indigenous pottery in contemporary practice. Indigenous pottery was blackened with ebony seed in some local pottery communities whereas others used sawdust and green leaves and grass during firing to achieve the same finish. These finishes were possible because they used the open firing technique but in this case, because an electric kiln was used 
for the firing, it would be impossible to throw in any combustible material to blacken the wares.

There was a sense of uniqueness and individuality with indigenous pottery types because the firing temperature were not controlled like how the contemporary type is been controlled. But the use of manganese also offers potters the freedom to wipe and deepen application of manganese to give unique finishes.

\section{Conclusions}

Berns [5] affirms that a closer look at contemporary pottery exposes the gender biases that honour men's "high" over women's "low" craft, making men the presumed creators of these works. This is as a result of the introduction of ceramics by the Europeans through colonization which changed the style and approach of pottery from the usual domestic wares to more sophisticated sculptural pieces. The change in presentation and the representation of the practice have, however, been modelled in this process and caused women to be further marginalized. The educational upbringing and work makes us look for female mentors and so we struggle with our artistic ideas and even our identity as women [16]. In trying to connect with others who had feelings of doubts of being female ceramic artists and educators, the motivation was to explore feminine features in seashells that would amend the current trend to resurrect women's participation in formally trained pottery.

Studying both indigenous and contemporary ceramic productions reveals similarities in techniques employed. Women were the first makers of clay objects and that females are often associated with nature, earth and domesticity since they double as both the bread makers and home managers. Weida [16] has specified that as potters, we speak in physical references to the body and the pot ("lip", 'foot", "belly", and "shoulder" of the vessel). This reference of pottery to the body informed the development of ceramic crockery from the seashell which was identified as the appropriate feminine idiom for the project.

So much experience has been gained with this project; owing to the fact that women ceramists (both potters and ceramic sculptors) are faced with a unique history and heritage. Being interested in feminism does not mean women feel troubled by men we are different in form, beliefs and reasoning. If pots are about our bodies and women make pots, then the pots communicate some meaning to its audience. The shape and function of pottery can lead to mixed feelings in female potters who embrace bodily meanings of pottery and may avoid ideas of stereotypical femininity.

One may also wonder what possibilities are left for female artists if they choose to engage in pottery production once again. How can the female potter reclaim her own thought, autonomy, and originality in the making and use of her pottery products? Both genders have had some western associations with pottery practices but there is a feminine touch missing in the contemporary pottery practice which could be the underlying cause of less female participation in the current trend. In this project work, an attempt has been made to map out roles of physicality and femininity within the many relationships between gender and pottery. This study has touched on space in terms of domestic area and work spaces as they impact, define and are defined by women's artistic processes and prowess which means that an emphasis on women is currently important in the field of ceramic art.

From the research findings and conclusions drawn, it is recommended that:

There are concerns that gender identity and gender specific behaviour could be attributed to instinctive influences. This factor plays a role and its relative importance may possibly be investigated to create an opportunity that would rejuvenate complementary gender roles in the practice where practitioners, especially female students would be given the chance to develop concepts that would depict their inner values and beliefs in their wares; this could be dependent on the person's gender. Simple studio forming techniques such as 'modelling', 'throwing' and 'pressing' could be used to make wonderful pieces in isolation or by blending two or more. Both the indigenous and contemporary ceramic practices can use available simple finishes to enhance the aesthetic value of the wares.

Additionally, there could be an education which enlightens and gives a sense of freedom in understanding the history of pottery and its makers. In understanding the history of the practice and the effects of colonialism, feminism can serve as a source of validation and empowerment to female students and practitioners. This education can focus on the difference between pottery and ceramic sculpture to help students and potters carve a niche for themselves in designing and producing outstanding forms for their wares.

\section{References}

[1] Perani, J. and Smith, F. T. (1998). The Visual Arts of Africa: Gender, Power and Life Cycle rituals. New York. PrenticeHall.

[2] Barley, N. (1994). Smashing Pots: Works of Clay from West Africa. Washington D. C: Smithsonian Institute Press.

[3] Anquandah, J. A. (2006). The Traditional Potter's Craft, Accra; National Commission on Culture.

[4] Rattray, R. S. (1927). Religion and Art in Ashanti. Oxford: Clarendon Press.

[5] Berns, M. C. (1993), Art, history and Gender: Women and clay in West Africa. African Archaeological Review, 11 (1), 129-148.

[6] Annan, G. (2018). Tracing the Evolution of the Roles of Female Characters in Selected Works of Chinua Achebe. University of Ghana, Legon. Accra. Unpublished MPhil. thesis submitted to the University of Ghana.

[7] Asihene, E. V. (1978). Understanding the Traditional Art of Ghana: Cranbury, New Jersey: Associated University Press, Inc. 
[8] Cooper, E. (2000). Then Thousand Years of Pottery (4th ed). British Museum Press. p 7.

[9] Priddy, B. (1974). Pottery in Upper Region. National Museum of Ghana Occasional Papers, No. 6, 8, 41-51.

[10] Peterson, S. and Peterson, J. (2003). The Craft \& Art of Clay: a complete potter's handbook, (4th ed). London. Laurence King Publishing Ltd, p 108.

[11] Tourtillott, S. J. E. (2009). 500 Ceramic Sculptures: Contemporary Practice, Singular Works. New York: Lark Books, p. 1.

[12] Quinn, A. (2007). Ceramic Design Course: Principles, practice, and techniques: a complete guide for ceramicists. New York: Barron's Educational Series, Inc. pp. 10, 14, 20.
[13] Hopper, R. (2000). Functional Pottery: Form and Aesthetic in Pots of purpose, Krause Publications Craft, pp. 9, 15, 29, 100, 165.

[14] Hodgekiss, A. (2013). Eating Hot Food off Plastic Plates can cause Increase the Risk of Kidney Stones. Retrieved from: http://www.dailymail.co.uk/health/article. [Accessed Date: 6th September, 2018].

[15] Vicchio, M. D. (2001). Postmodern Ceramics. Thames \& Hudson Inc. p 106, 124, 134.

[16] Weida, C. L. (2011). Artistic Ambivalence in Clay: Portraits of Pottery, Ceramics, and Gender. UK. Cambridge Scholars Publishing. 